\title{
Implementation of Type-2 Fuzzy Logic Controller in PMSM Drives Using DSP
}

\author{
S. Wahsh', Y. Ahmed ${ }^{2}$, E. Abo Elzahab ${ }^{3}$ \\ ${ }^{1,2}$ Department of Power Electronics and Energy Conversion, Electronics Research Institute, Giza, Egypt \\ ${ }^{3}$ Department of Electrical Power and Machines, Cairo University, Giza, Egypt
}

\section{Article Info \\ Article history: \\ Received Oct 30, 2017 \\ Revised Apr 24, 2018 \\ Accepted Aug 6, 2018}

\section{Keyword:}

Direct torque control Fuzzy logic controller Fuzzy type-2 PMSM

Space vector modulation

\begin{abstract}
This paper presents interval type-2 fuzzy logic (IT2FL) controller applied on a direct torque controlled (DTC) permanent magnet synchronous motor (PMSM), using digital signal processing (DSP). The simulation of PMSM with space vector pulse widths modulation (SVPWM) inverter presented under several operating condition. To verify the simulation results a hard ware setup is prepared and tested at several operating conditions using dspace 1102 DSP model. The experimental and simulation results are in agreement, the torque dynamic response is very rapid and the system achieves the steady state in a very short time.
\end{abstract}

Copyright $(0) 2018$ Institute of Advanced Engineering and Science. All rights reserved.

\section{Corresponding Author:}

S. Wahsh,

Department of Power Electronics and Energy Conversion,

Electronics Research Institute,

33 El-Tahrirst., Dokki, Giza, Egypt

Email:wahsh@eri.sci.eg

\section{INTRODUCTION}

Fuzzy logic systems (FLS) have been successfully applied to control complex or ill-defined processes whose mathematical models are difficult to obtain. The ability of converting linguistic descriptions into automatic control strategy has made it a practical and promising alternative to the classical control scheme for achieving control of complex nonlinear systems.

The concept of type-2 fuzzy sets was initially proposed by Zadeh as an extension of typical fuzzy sets (called type-1). Mendel and Karnik developed a complete theory of IT2FL systems. Recently, T2FLSs have attracted more attention in many literatures and special issue of IEEE Transactions on Fuzzy systems. A decentralized adaptive controller based on type-2 fuzzy systems has been presented by [1], the controller used to maintains the tracking errors in PMSM based on field oriented control. An adaptive IT2FLCcontroller is proposed in [2] for PMSM drives, Type-2 fuzzy logic system combined with adaptive control to achieve accurate control system which able to track the refence speed in a system with higher uncertainties.

IT2FL systems are more complex than type-1, the major difference being the present of type- 2 is their antecedent and consequent sets. IT2FL systems result better performance than type-1 fuzzy logic systems on the applications of function approximation, modeling and control [2]-[8]. The wide ranges of applications of type-2 FLS have shown that it provide good solutions, especially in the presence of uncertainties as

a. Uncertainties in inputs to the FLC which translate to uncertainties in the antecedent Membership Functions (MFs).

b. Uncertainties in control outputs which translate to uncertainties in the consequent MFs of the FLC. 
c. Linguistic uncertainties as the meaning of words that are used in the antecedent and consequent linguistic labels can be uncertain-words mean different things to different people.

In the mid 1980's the direct torque control (DTC) was introduced for induction motor by Takahashi et al. In the 1990's, DTC for permanent magnet synchronous motor (PMSM) was developed. Compared with field oriented control, the DTC has many advantages such as less machine parameter dependence, simpler implementation and quicker dynamic torque response. There is no current controller needed in DTC, because it selects the voltage space vectors according to the errors of flux linkage and torque. DTC has some drawbacks, such as the high torque and flux ripples. Due to sophisticated and large computational of vector control DTC recognized as a viable solution to achieve these requirements and reduce the complexity of vector control.

In this article, DTC technique used to control the speed of the PMSM, the speed controller is represented by IT2FL, the torque and flux regulators are represented by conventional PI controllers. The controller's parameters are adjusted for minium traking error, the system implemented and tested at different operating conditions using DSP.

\section{PMSM MATHEMATICAL MODEL AND DIRECT TORQUE CONTROL PRINCIPLE}

The stator flux linkage vector $\psi \mathrm{s}$ and rotor flux linkage $\psi \mathrm{m}$ can be drawn in the rotor refence frame (d-q), stator reference frame (ds-qs) and stationary reference frame $(\alpha-\beta)$ as shownin Figure 1 [9]-[12].

$$
\begin{aligned}
& \mathrm{Vd}=\boldsymbol{r} \mathrm{s} . \mathrm{id}-\boldsymbol{w r} \psi q+\boldsymbol{p} \cdot \boldsymbol{\psi} \boldsymbol{d} \\
& \mathrm{V} q=r \mathrm{~s} . \mathrm{iq}+w r \psi d+\boldsymbol{p} \cdot \psi \boldsymbol{q} \\
& \psi d=L \mathrm{~d} . \mathrm{i}+\psi \boldsymbol{m} \\
& \psi q=L q \cdot i q \\
& \mathrm{~T} e=\frac{3}{2} \mathrm{p}(\psi \mathrm{d} . \boldsymbol{i q}-\boldsymbol{\psi q} \cdot \boldsymbol{i d})
\end{aligned}
$$

Where vd, and vq are the $\mathrm{d}-\mathrm{q}$ axis voltages, id and iq are the $\mathrm{d}-\mathrm{q}$ axis stator currents, Ld and Lq, are the d-q axis inductances, $\Psi \boldsymbol{d}$, and $\Psi \boldsymbol{q}$, are the d-q axis stator flux linkages, $r \boldsymbol{s}$ is the stator resistance per phase, $W r$ the rotor speed and $\Psi m$, is the stator flux linkage due to the rotor magnets. By transforming the rotor reference flux component $\psi \mathrm{d}, \psi \mathrm{q}$ and current $\mathrm{id}$, iq to the stator reference flux component $\psi \mathrm{ds}, \psi \mathrm{qs}$ and current component ids, iqs with the transformation (6) and (7), torque (5) can be transformed as in (8).

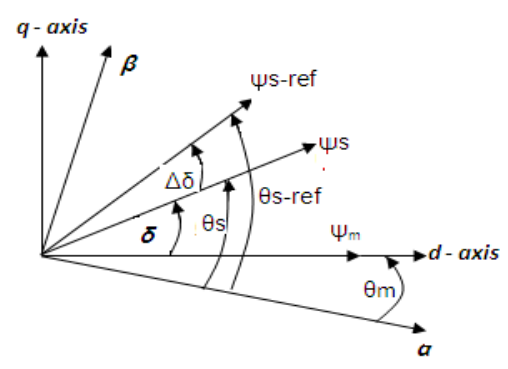

Figure 1. The stator and rotor flux linkages in different reference frame

$$
\begin{aligned}
& {\left[\begin{array}{l}
\text { ids } \\
\text { iqs }
\end{array}\right]=\left[\begin{array}{cc}
\cos \delta & \sin \delta \\
-\sin \delta & \cos \delta
\end{array}\right]\left[\begin{array}{l}
\text { id } \\
\text { iq }
\end{array}\right]} \\
& \sin \delta=\frac{\psi d}{\psi s} \text { and } \cos \delta=\frac{\psi q}{\psi s}
\end{aligned}
$$




$$
\begin{aligned}
& \mathrm{T} e=\frac{3}{2} \frac{1}{\mathrm{Ls}} p|\psi s \|| \psi \mathrm{m} \mid \sin \delta \\
& \psi \mathrm{s}=\int(\mathrm{vs}-i s . \mathrm{R}) d t \\
& \Delta T \mathrm{e}=\left(\frac{3}{2} \frac{1}{\mathrm{Ls}} p|\psi s \|| \psi \mathrm{m} \mid \cos \llbracket \delta\right) \rrbracket \Delta \delta
\end{aligned}
$$

Equation (10) shows that to increase torque, $\delta$ should be increased; to increase $\delta$ stator flux should turn faster than rotor flux by the selection of optimum voltage vector according to difference between the reference and actual values of torque and flux.

\section{SPACE VECTOR MODULATION}

The main advantages of the space vector modulation (SVM) are: A 15\% increase in DC link voltage utilization compared with the sine-triangle technique. Lower harmonic content, particularly at high modulation indices compared with the sine-triangle technique [11].

The voltage-vector space is divided up into six sectors in the vector space as shown in voltagevector space in Figure 2. In one sampling interval, the output voltage vector can be written as

$$
\mathrm{U}=\frac{\mathrm{t} 0}{\mathrm{Ts}} \mathrm{U} 0+\frac{\mathrm{t} 1}{\mathrm{Ts}} \mathrm{U} 1+\cdots+\frac{\mathrm{t} 7}{\mathrm{Ts}} \mathrm{U} 7
$$

Where $t_{0}, t_{1}, \ldots \ldots \ldots, t 7$ are the turn-on time of the vectors $\overrightarrow{\mathrm{U}_{0}}, \ldots ., \overrightarrow{\mathrm{U} 7}, t_{0}, t_{1}, \ldots ., t_{7} \geq 0, \sum_{\mathrm{i}=0}^{\mathrm{i}=7} \mathrm{ti}=\boldsymbol{T s}$ and $T s$ is the switching time. However, in order to reduce the number of switching actions and make full use of active turn-on time for space vectors, the vector $U$ is commonly split into the two nearest adjacent voltage vectors and zero vectors $U_{0}$ and $U_{7}$ in an arbitrary sector. For example, in sector $I$, in one sampling interval, vector $\mathrm{U}$ can be expressed as:

$$
\mathrm{U}=\frac{\mathrm{T} \mathbf{1}}{\mathrm{Ts}} \boldsymbol{U} 1+\frac{\mathrm{T} 2}{\mathrm{Ts}} \mathrm{U} 2+\frac{\mathrm{T} 0}{\mathrm{Ts}} \boldsymbol{U} \mathbf{0}+\frac{\mathrm{T} 7}{\mathrm{Ts}} \mathrm{U} 7
$$

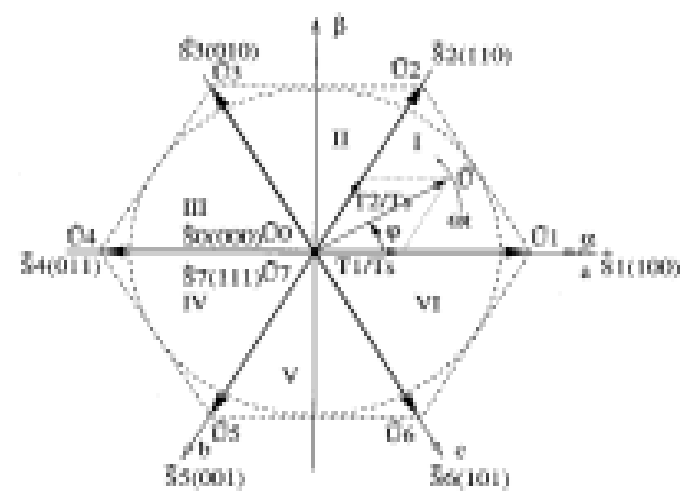

Figure 2. Voltage vector space

\section{INTERVAL TYPE -2 FUZZY LOGIC SYSTEM}

In order to represent an IT2F set, we use two membership functions called upper membership (UMF) and lower membership (LMF) [13]-[18]. Uncertainty of the primary membership grade of a type-2 
MF consist a bounded region that called footprint of uncertainty (FOU) which models the uncertainties in the shape and position of the type-1 fuzzy set. Shown in Figure 3.

An UMF and a LMF are two type-1 MFs that are bounds for the FOU of an interval type-2 MF. The UMF is a subset that has the maximum membership grade of the FOU, and the LMF is a subset that has the minimum membership grade of the FOU Figure 4.

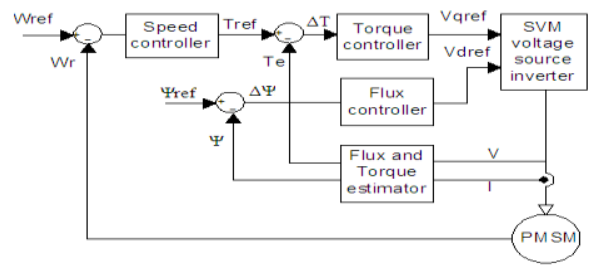

Figure 3. Block diagram of a PMSM drive with DTC-SVM system

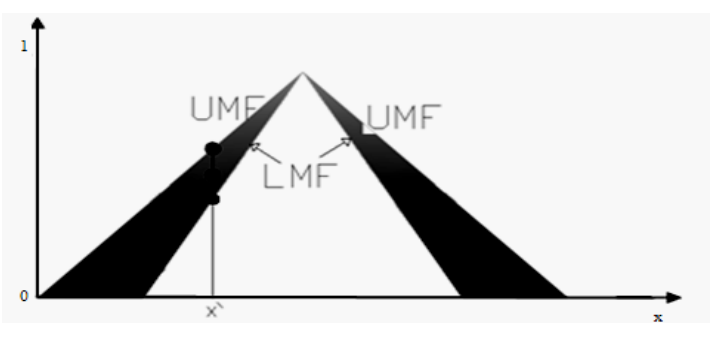

Figure 4.Membership Function of Fuzzy type-2

A IT2FLS consists of four basic elements Figure 5: the type-2 fuzzyfier, the fuzzy rule-base, the inference engine, and the type-2 type reduction/defuzzifier. The IT2FL system works as follows, the crisp inputs from the input sensors are first fuzzified into input type-2 fuzzy sets. The input type-2 fuzzy sets then activate the inference engine and the rule base to produce output type- 2 fuzzy sets. The type-2 FLC rules will remain the same as in a type-1 FLC but the antecedents and/or the consequents will be represented by IT2F sets. The inference engine combines the fired rules and gives a mapping from input type-2 fuzzy sets to output type-2 fuzzy sets. The type- 2 fuzzy outputs of the inference engine are then processed by the typereducer which combines the output sets and performs a calculation which leads to type-1 fuzzy sets called the type-reduced sets. After the type-reduction process, the type-reduced sets are defuzzified to obtain crisp outputs that are sent to the actuators [14]-[16].

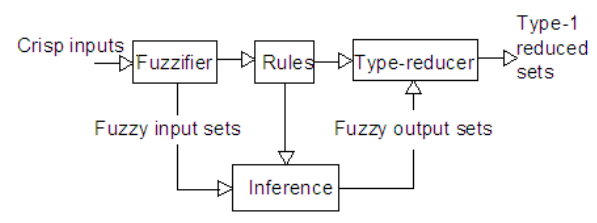

Figure 5. Configuration of a fuzzy type-2 logic system

It has been argued that using IT2F sets to represent the inputs and/or outputs of FLCs has many advantages when compared to type-1 fuzzy sets; we summaries some of these advantages as follows:

1. As the type-2 fuzzy set membership functions are themselves fuzzy and contain a footprint of uncertainty, they can model and handle the linguistic and numerical uncertainties associated with the inputs and outputs of the FLC. Therefore, FLCs that are based on type-2 fuzzy sets will have the potential to produce a better performance than type-1 FLCs when dealing with uncertainties.

2. Using type-2 fuzzy sets to represent the FLC inputs and outputs will result in the reduction of the FLC rule base when compared to using type- 1 fuzzy sets as the uncertainty represented in the footprint of uncertainty in type-2 fuzzy sets lets us cover the same range as type-1 fuzzy sets with a smaller number of labels. The rule reduction will be greater as the number of the FLC inputs increases.

3. Each input and output will be represented by a large number of type-1 fuzzy sets which are embedded in the type- 2 fuzzy sets. The use of such a large number of type-1 fuzzy sets to describe the input and output variables allows for a detailed description of the analytical control surface as the addition of the extra levels of classification gives a much smoother control surface and response.

4. It has been shown that the extra degrees of freedom provided by the footprint of uncertainty enables a type-2 FLC to produce outputs that cannot be achieved by type-1 FLCs with the same number of membership. 
A standard approach for speed control in drives is the use of a PI controller. Recent developments in artificial intelligence based control have brought in to focus a possibility of replacing a PI controller with a fuzzy logic (FL).

The membership functions for input and output variables for the PI-type fuzzy type-2 are speed error $(E)$, change of speed error $(\Delta E)$, and change of torque as output $(\Delta T)$.

\section{EXPERIMENTAL DRIVE CONFIGURATION}

The laboratory set-up built for experimental tests of the PMSM drive system consists of the following main parts:

1. PMSM BeckhoffAM 247 Series with resolver.

2. Beckhoof AX2513 series digital servo amplifier.

3. DSP (DSPACE DS1102) model.

4. PC Pentium 2, 32MB of RAM, 1GB of ROM with Windows and DSP Processor.

5. PC Pentium 4, CPU $3 \mathrm{GHz}, 1 \mathrm{~GB}$ of RAM with Windows XP and Beckhoff Motor software.

6. MCRT $48200 \mathrm{~V}$ digital torque transducer.

7. Tektronix digital storage oscilloscope TPS2024 model.

8. Dc generator and resistive load

The overall system as shown in Figure 6 consists of the PMSM with built in resolver and shaft encoder in order to measure the motor position, another component in the system is the BECKHOFF digital servo amplifier which drive the motor using space vector PWM technique, also, there are output group of sensors to measure the actual motor currents, voltage, and torque. This system is controlled using DSP implemented in computer system using Matlab software.

\section{SIMULATION AND EXPERIMENTAL RESULTS}

There are many control strategies for DTC PMSM drives. Fuzzy typ-1 was used in control of DTC PMSM drives and now we apply IT2FLS. IT2FL controller is used for speed loop, torque and flux loops controllers are of conventional PI controller type [19]-[23]. The system is modeled with MATLAB SIMULINK using PMSM data in appendix (A), with switching time Ts=0.0002sec. Figure 7 shows the speed response at $2000 \mathrm{rpm}$ reference speed, while Figure 8 shows the load torque response (TL) at load step change from $0.55 \mathrm{NM}$ to $1.1 \mathrm{~N} . \mathrm{M}$ at $1 \mathrm{sec}$ time, Figure 9.shows the current response. Motor torque and reference torque is shown in Figure 10.
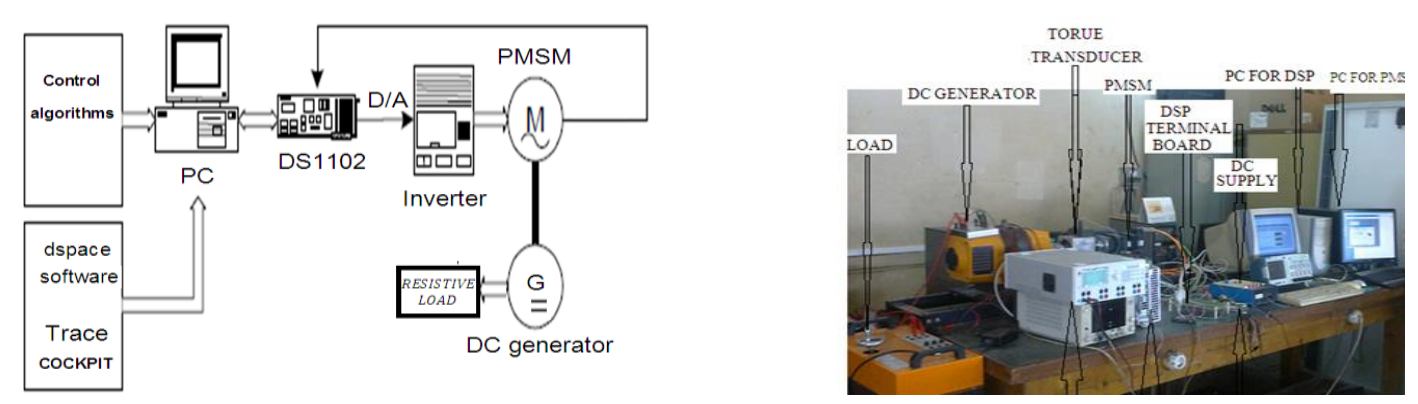

Figure 6. Laboratory Set-up 


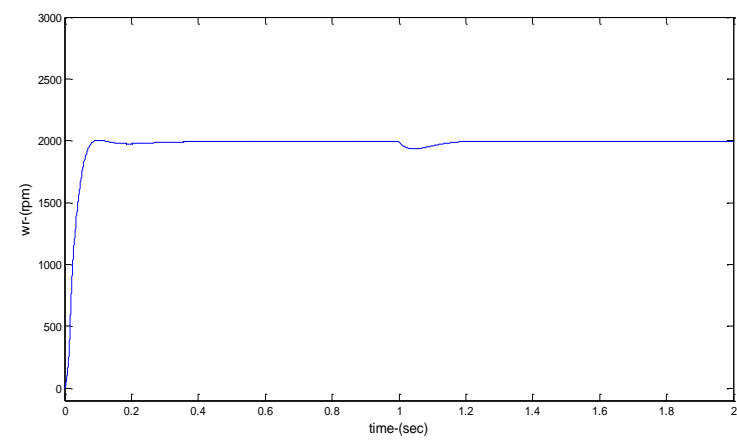

(a)Simulation

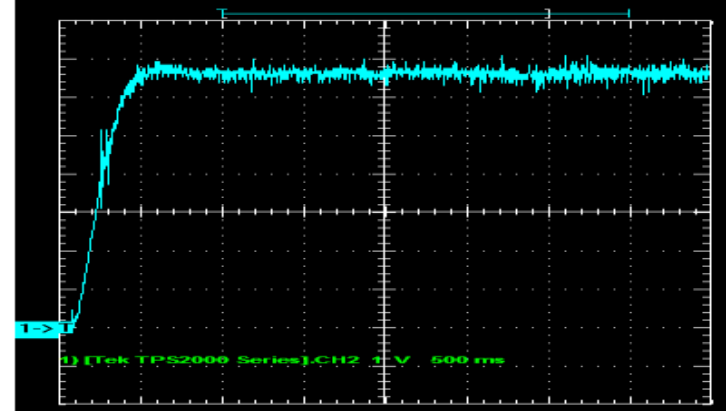

(b) Experimental

Figure 7. Speed Response

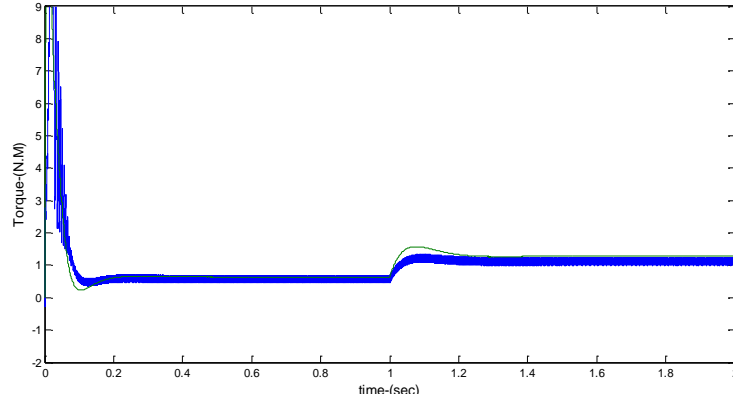

(a)Simulation

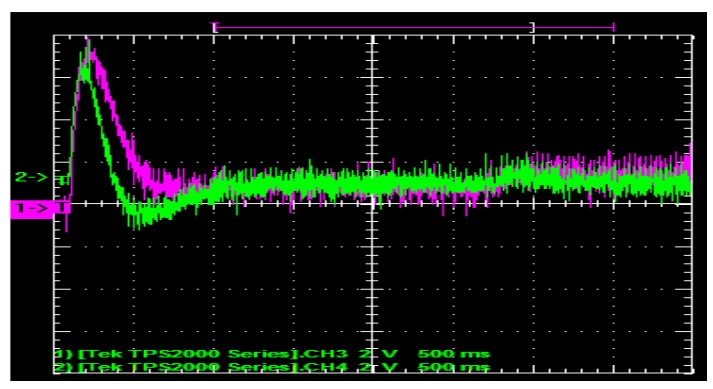

(b) Experimental

Figure 8. Torque Response

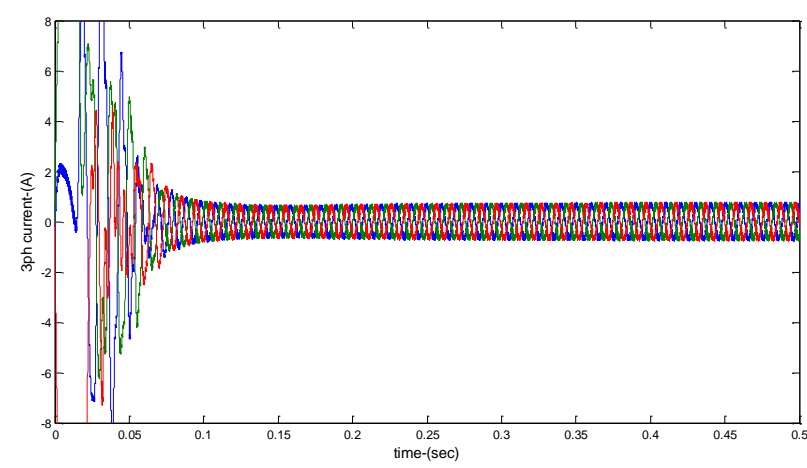

(a)Simulation

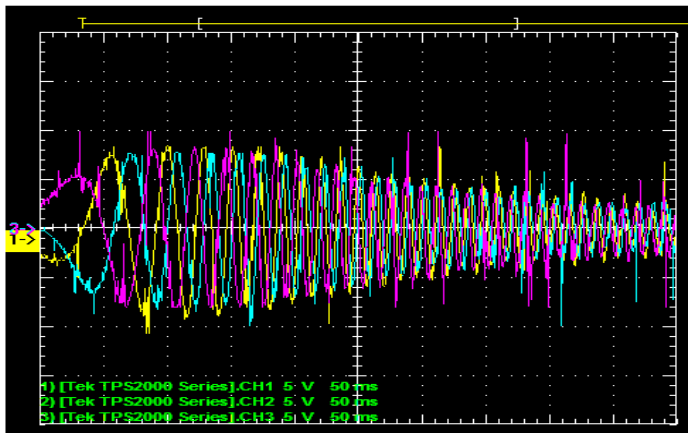

(b) Experimental

Figure 9. Three phase Current Response

\section{CONCLUSION}

This paper presents modeling, simulation and implementation of a speed control in PMSM drive based on DTC technique. IT2FL utilized as a speed controller, since it provides additional degrees of freedom and handles systems uncertainties. The drive system has been simulated and tested using MATLAB SIMULINK. Simulation and experimental are presented under different operating conditions. A hardware setup is implemented and tested using dspace 1102 DSP board. The results show that the system operation more smooth and reaches steady state faster when using fuzzy type-2 with the same number of memberships as compared to conventional fuzzy. The system reaches steady state in $700 \mathrm{~ms}, 1.5 \%$ speed overshot, $1.35 \%$ speed ripples and zero steady state speed error experimentally. The results show good agreement between simulation and test results. 
APPENDIXES

Appendix 1. PMSM Parameters

\begin{tabular}{cc}
\hline Data & Value \\
\hline Rated speed & $3000 \mathrm{rpm}$ \\
Rated torque & $2.2 \mathrm{~N} . \mathrm{M}$ \\
$\mathrm{p}$ & 6 \\
$\mathrm{R}$ & $11.0 \mathrm{ohm}$ \\
$\mathrm{Ld}$ & $25 \mathrm{mH}$ \\
$\mathrm{Lq}$ & $25 \mathrm{mH}$ \\
$\mathrm{J}$ & $1.6 \mathrm{Kg}-\mathrm{cm}^{2}$. \\
Ym & $0.295 \mathrm{~Wb}$ \\
Vdc & $350.0 \mathrm{volt}$ \\
$\mathrm{Ts}$ & $0.0002 \mathrm{sec}$ \\
\hline
\end{tabular}

\section{REFERENCES}

[1] S.A. Barkat, A. Tlemçani and H. Nouri, "Noninteracting Adaptive Control of PMSM Using Interval Type-2 Fuzzy Logic Systems," in IEEE Transactions on Fuzzy Systems, Oct. 2011, vol. 19, no. 5, pp. 925-936.

[2] H. Chaoui, M. Khayamy and A. A. Aljarboua, "Adaptive Interval Type-2 Fuzzy Logic Control for PMSM Drives With a Modified Reference Frame," in IEEE Transactions on Industrial Electronics, May 2017,vol. 64, no. 5, pp. 3786-3797.

[3] R.John and S.Coupland,"Type-2 Fuzzy Logic and the Modeling of Uncertainty in Applications", Human-Centric Information Processing, SCI 182, Verlag Berlin Heidelberg 2009,pp 185-201.

[4] J.M. Mendel .,"Type-2 Fuzzy Sets and Systems: An Overview", IEEE Computational Intelligence Magazinem 2007, no.2, pp 20-29.

[5] O.Castillo, N.Cazarez and D.Rico," Intelligent Control of Dynamic Systems Using Type-2 Fuzzy Logic and Stability Issues", International Mathematical Forum 2006, vol.28, pp 1371 - 1382.

[6] J.M Mendel, F. Liu. and D.Zhai D," $\alpha$-plane Representation for Type-2 Fuzzy Sets: Theory and Applications, IEEE Transactions on Fuzzy Systems 2009,vol. 17,no. 5, pp 1189-1207.

[7] H.Tahayori, A.G.B.Tettamanzi. and G.D. Antoni ,"Approximated Type-2 Fuzzy Set Operations", IEEE International Conference on Fuzzy Systems, Vancouver, BC, Canada 2006,pp 1910 - 1917.

[8] M.Hsiao ,Li Ying, T.S.Hseng ,J.Z.Lee., C.H.Chao. and S.H.Tsai.,"Design of Interval Type-2 Fuzzy Sliding-mode Controller", Information Sciences 2008, vol.178,pp 1696-1716.

[9] M. Yuhendri, A. Aswardi, "Direct Torque Control Strategy of PMSM Employing Ultra Sparse Matrix Converter", International Journal of Power Electronics and Drive System (IJPEDS), March 2018, vol. 9, no. 1, pp. 64-72.

[10] T. Sutikno,"The Preliminary Resarch for Implemention of Improved DTC Scheme of High Performance PMSM Drives Based on FPGA", Telkomnika, Telecommunication, Computing, Electronics and Control, 2008. vol.6,, pp $155-166$

[11] S.Wahsh ,M.Abd El Aziz and Y.Ahmed ,"Fuzzy Logic Control of Direct Torque Control PMSM Drives Using Space Vector Technique," SCIS\&ISIS conf., Tokyo, Japan 2006, pp 766-771.

[12] Y.Li,, M.Jian,.Y.Qiang, and L.Jiangyu, ,"A Novel Direct Torque Control Permanent Magnet Synchronous Motor Drive Used in Electrical Vehicle.", International Journal of Power Electronics and Drive Systems (IJPEDS), 2011,vol.1,no.2,

[13] K.Chikh, ,A.Saad., M.Khafallah, ,D.Yousfi., F.Z.Tahiri, and M.A.Hasoun, ,"Constant Switching Frequency DTC for PMSM Using Low Switching Losses SVM-an Experimental Result., International Journal of Power Electronics and Drive Systems, (IJPEDS), 2017,vol 8,no.2, pp558.

[14] H.Chaoui, K.Mehdy and A.Abdullah,"Adaptive Interval Type-2 Fuzzy Logic Control for PMSM Drives with a Modified Reference Frame," IEEE Transactions on IA 64.5, 2017,pp 3786-3797.

[15] S.Wahsh ,M.Abd El Aziz and Y.Ahmed "Fuzzy Type 2 Controller for Different Direct Torque Control PMSM Drives Using Space Vector Techniques” Journal of Electrical Engineering (Jee) 2013, Edit. 4, vol. 13,,pp 95-103

[16] P. Brandstetter and M.Mech ,"Control Methods for Permanent Magnet Synchronous Motor Drives with High Dynamic Performance, EPE’95, Sevilla, Spain 1995,vol. 3,pp805- 3.810.

[17] A.M. Miguel and C.A.Peña-Reyes.," Hardware Architecture and FPGA Implementation of a Type-2 Fuzzy System, GLSVLSI'04, Boston, Massachusetts, USA 2004, pp 451 - 461.

[18] O.Castillo ,P. Melin and J.R. Castro ,"Computational Intelligence Software for Interval Type-2 Fuzzy Logic", Proc.of Workshop on Building Computational Intelligence and Machine Learning ,2008,pp 9 -13.

[19] Hicham C. and Pierre S.: Adaptive fuzzy logic control of permanent magnet synchronous machines with nonlinear friction, IEEE Transactions on Industrial Electronics vol. 59,Issue: 2, Feb. 2012,pp 1123- 1133

[20] H.Yassin, H.Hanafy, and M. Mohab ," Enhancement Low-voltage Ride Through Capability of Permanent Magnet Synchronous Generator-based Wind Turbines Using Interval Type-2 Fuzzy Control, IET Renewable Power Generation, 2016,vol.10,no.3 ,pp 339-348.

[21] C.Wanmin, and S. Tong,"Adaptive Fuzzy Tracking Control Design for Permanent Magnet Synchronous Motor with Output Constraint ,Nonlinear Dynamics, 2017,vol.87,no.1 ,pp 291-302.

[22] Feng, Guodong, Chunyan Lai, and Narayan C. Kar:A :Closed-loop Fuzzy-logic-based Current Controller for PMSM Torque Ripple Minimization using the Magnitude of Speed Harmonic as the Feedback Control Signal ", IEEE Transactions on IA 64.no.4 ,2017,pp 2642-2653. 
[23] S.Wahsh ,M.Abd El Aziz and Y.Ahmed., "Experimental Investigation of Fuzzy Logic Controller Types 1 and 2 in PMSM Drives Using DSP," International conf. on Applied Analysis and Mathematical Modeling (ICAAMM 2015),8-12 June 2015,Istunbal,Trukey.

\section{BIOGRAPHIES OF AUTHORS}

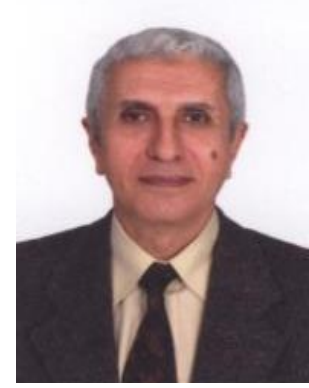

Prof. S. WAHSH received his B.Sc. degree in Electrical Engineering from AinShamsUniversity, Cairo, in June 1967. In 1973 he joined the National Research Center (NRC) as a researcher. He received his Ph.D. in Electric Drives from Budapest Technical University, Hungary in January 1980.Since 1980 he has been working as an assistant professor in the Electronics Research Institute (ERI). From 1984 till 1998 he was head of Power Electronics and Energy Conversion Dept., ERI. In 1990 he became a professor of Power Electronics in ERI. He has authored more than a hundred thirty articles in the field of modeling, analysis and control of DC, IM, SRM and PMSM. Furthermore, he has supervised several M Sc and $\mathrm{PhD}$ thesis. He has also managed several projects as principal investigator. Prof. Wahsh works part time in various Egyptian universities. He also is acting as member in evaluating committee of university staff. He was a visiting professor for various foreign universities. He has done a considerable amount of consulting engineering work in Industrial Electronics .His major field of interest includes Power Electronics, Electric Drives, Motion Control and Electrical/Hybrid Vehicles.

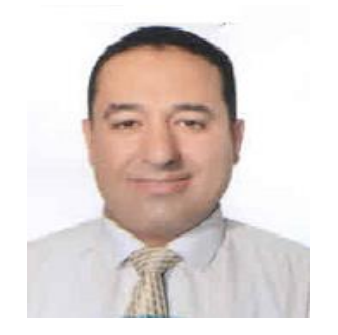

Dr. Yasser obtained his B.SC from Tanta university faculty of engineering, electrical power and machine department 1999 He works at Electronics Research Institute (ERI).in Power Electronics and energy conversion department since 2001. Dr. Yaser obtained his Msc and $\mathrm{PhD}$ from Cairo University at 2006 and 2014. His major interest are :Electrical drives control, Electric and hybrid electric vehicles modeling, simulation, and control. Modeling and simulation of electrical systems.

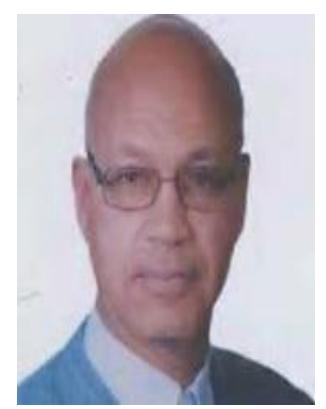

Prof.Abou El-Zahab, born at 1948. He obtained his B.Sc. (Very Good with honors), M.Sc. Electrical Engineering, Cairo University, Egypt at 1970, 1974and Ph.D. University of Paul Sabatier, France, 1979.He appointed Teaching Assistant, 1970, Assistant Prof. 1985, and Prof. Electrical Power and Machines Department, Cairo University 1990. He works as visiting Professor, University of Calgary, Canada 1991, 1992, United Arab Emirates University, UAE 1997 and 1999. Prof. Abou El-Zahab works part-time at Interdisciplinary Engineering Program, American University in Cairo, and Professor, Petroleum Engineering Department, 2004, 2009. His consulting engineering includes (member of Electrical Engineering Consulting Group), Design of Lighting and Electrical Distribution System in different industrial, commercial and institutional projects, registered: Professional Engineer, Egypt. Principal member in the Egyptian Society and Egyptian Syndicate of Engineers. He won prize for graduate studies research, Cairo University 1998 and 2004. 